\title{
Short communication: Appropriate and alternative methods to determine viable bacterial counts in cow milk samples
}

\author{
G. Loss, ${ }^{*}{ }^{1}$ S. Apprich, $¥$ W. Kneifel,‡ E. von Mutius,§ J. Genuneit,\# and C. Braun-Fahrländer, ${ }^{\star} \dagger$ \\ on behalf of the GABRIEL study group \\ *Swiss Tropical and Public Health Institute, Socinstrasse 57, PO Box, 4002 Basel, Switzerland \\ †University of Basel, Petersplatz 1, 4003 Basel, Switzerland \\ $\ddagger B O K U$ Vienna, University of Natural Resources and Life Sciences, Department of Food Science and Technology, Muthgasse 18, \\ A-1190 Vienna, Austria \\ §LMU Munich, University Children's Hospital, Lindwurmstrasse 4, D-80337, Munich, Germany \\ \#Ulm University, Institute of Epidemiology and Medical Biometry, Helmholtzstraße 22, D-89081 Ulm, Germany
}

\begin{abstract}
Farm milk consumption is reported to be inversely related to the development of asthma and atopy in children and it has been hypothesized that microorganisms in milk might contribute to this protective effect. The GABRIEL study was designed to investigate this hypothesis in a large population of European children, calling for a rapid alternative to classical culture techniques to determine bacteriological properties of milk samples. One objective was to evaluate 2 different rapid methods to determine bacteriological properties in a large number of cow milk samples collected under field conditions. BactoScan (Foss Analytical, Hillerød, Denmark), an automated standard flow cytometric method utilized for routine testing of milk quality, and TEMPO (bioMérieux, Marcy l'Etoile, France), an automated most-probable-number method, were used to assess the total viable bacterial count in farm and commercial milk samples. Both methods were compared with standard plate count method and each other. Measurements based on the TEMPO method were in good agreement with the standard plate count method and showed reliable results, whereas BactoScan results did not correlate with standard plate count measurements and yielded higher bacteria counts in heat-treated milk samples compared with raw milk samples. Most likely, these discrepant results were due to inferences with staining reactions and detection of bacteria in heattreated milk samples. We conclude that, in contrast to the routinely used BactoScan method, the TEMPO method is an inexpensive and rapid alternative to standard culture methods suitable to assess total bacterial counts in processed and raw milk samples.
\end{abstract}

Received September 2, 2011.

Accepted January 29, 2012.

${ }^{1}$ Corresponding author: georg.loss@unibas.ch
Key words: microorganism, total viable count, milk, childhood asthma

\section{Short Communication}

Previous epidemiological studies have shown that consumption of farm milk is associated with less childhood asthma and atopy (Riedler et al., 2001; Waser et al., 2007; Loss et al., 2011). The hygiene-hypothesis states that infections or microbial exposure in early childhood decrease the risk for allergy development (Strachan, 1989). The microbial load of unpasteurized milk thus offers a possible explanation for the protective effect of farm milk (Perkin and Strachan, 2006). To establish valid associations of environmental exposures and health outcomes, large numbers of samples are required. The standardized classical culture method is regarded as the gold standard to determine microbiological properties of foods. However, a serious drawback is that it is laborious and time consuming to perform. During recent decades, several rapid methods have been developed, reducing the time, and thus cost, to obtain a microbiological test result. However, it remains a challenge to choose the ideal method for the user's practical context. Although molecular, immunological, and microscopic methods are automatable, rapid, less labor-intensive, and show better reproducibility compared with conventional methods, they require high investment for equipment and materials (Jasson et al., 2010).

The GABRIEL study (Multidisciplinary Study to Identify the Genetic and Environmental Causes of Asthma in the European Community) used 2 different rapid methods to analyze the total viable bacterial count (TVC) of milk samples that were collected at participants' homes during a field visit. BactoScan (Foss Analytical, Hillerød, Denmark) is a rapid flow cytometry system that is utilized in routine testing of bacteriological quality of milk where bacteria are 
stained with ethidium bromide and their optical characteristics are quantitatively measured by a focused light beam (Suhren and Walte, 1998; Jasson et al., 2010). The ready-to-use TEMPO system (bioMérieux, Marcy l'Etoile, France) is a modified culture method that makes use of vials with culture medium specific to the test and cards simulating the most-probablenumber method. It is based on an automated system that reduces workload and number of manipulations without the necessity of a full laboratory infrastructure (Torlak et al., 2008; Jasson et al., 2010). The aim of this communication is to compare the flow cytometry and the automated most-probable-number method to standard plate count measurements and to each other, and to suggest the most appropriate rapid method to measure the TVC in this epidemiological setting.

The cross-sectional GABRIEL study was conducted in rural areas in Germany, Switzerland, Austria, and Poland. Environmental samples were taken from a stratified random subsample of 895 Bavarian participants, and milk samples were collected in 2 periods of the year [October to December $(\mathrm{n}=543)$ and April to August ( $\mathrm{n}=744)$; Genuneit et al., 2011]. During a field visit at the participants' homes, trained field workers collected 9 aliquots of cow's milk $(6 \times 45 \mathrm{~mL}$ and $3 \times$ $20 \mathrm{~mL}$ per visit) as it was consumed by the child. Children consumed either boiled or unboiled milk directly from a farm or pasteurized or UHT commercial milk. Samples were transported on ice and frozen at $-18^{\circ} \mathrm{C}$ immediately after arriving at the laboratory. The TVC was assessed in 1,287 milk samples by flow cytometry (BactoScan) and by the TEMPO method (detection limit $=1 \mathrm{cfu} / \mathrm{mL}$ ) using TEMPO TVC (total viable count). For validation of the rapid methods, the viable count of every tenth milk sample was also assessed by SPC method (IDF Standard 100B; International Dairy Federation, 1991). All microbiological measurements were performed at the University of Natural Resources and Life Sciences (Vienna, Austria).

The heating status of all milk samples was defined by residual activity of the milk intrinsic enzymes alkaline phosphatase [fluorimetric method according to EN ISO 11816-1 (ISO, 2000); lower detection limit = $10 \mathrm{mU} / \mathrm{L}$ ) and lactoperoxidase (Reflectoquant, Merck KGaA, Darmstadt, Germany; lower detection limit $=5,000$ $\mathrm{mU} / \mathrm{L}$ ) at the Max Rubner Institut (Kiel, Germany) according to the EC council directive 92/46/EC. The measurements allowed the samples to be categorized as (1) commercial milk heated to at least $85^{\circ} \mathrm{C}(\mathrm{n}=986)$, (2) commercial milk heated to below $85^{\circ} \mathrm{C}$ (pasteurized commercial milk, $\mathrm{n}=72$ ), (3) farm milk heated to at least $72^{\circ} \mathrm{C}(\mathrm{n}=49)$, and (4) raw farm milk or farm milk heated to below $72^{\circ} \mathrm{C}(\mathrm{n}=180)$. For all analyses, staff was blinded to all milk properties.
Statistical analyses were performed with Stata/SE 10.1 for Windows (Stata Corp., College Station, TX), and TVC were expressed as geometric means with $95 \%$ confidence intervals.

Measurements using the TEMPO method were in good agreement with bacterial counts based on standard culture technique (Spearman rho $=0.81$ ), whereas BactoScan measurement did not correlate at all (Spearman rho $=-0.29$ ). Figure 1A illustrates the geometric mean levels of TVC measured with BactoScan and TEMPO in all 1,287 milk samples according to milk type and milk heating status. Figure $1 \mathrm{~B}$ shows bacterial levels measured with BactoScan, TEMPO, and SPC method in a subsample of 95 samples that were measured by all 3 methods. Total viable bacteria counts were high in raw farm milks when measured by both the BactoScan and TEMPO methods and became decreasingly lower in heated farm milk, pasteurized commercial milk, and high-heated commercial milk samples when measured by SPC or the TEMPO method. Conversely, BactoScan measurements showed significantly higher levels of total viable bacteria in heated farm and commercial milk samples compared with raw milk levels.

The 2 rapid methods to measure TVC in milk samples collected at study participants' homes showed contrasting results when compared with each other and to the standard culture technique. Only the TEMPO method yielded valid and appropriate results when both raw and heat-treated milk samples were analyzed. BactoScan was developed as an automated instrument to assess the bacteriological quality of raw milk (Suhren and Walte, 1998) and is widely used for routine quality control of milk (Jasson et al., 2010). In contrast to routine raw milk quality control, the present study aimed at analyzing milk samples as they were usually consumed by the participating children and their families. Thus, processed milk samples such as boiled farm milk as well as pasteurized and UHT milk purchased on the retail market were tested. The discrepant results obtained by the BactoScan flow cytometry method are most likely explained by the presence of proteins and lipid globules in heated milk that have been reported to bind nonspecifically to fluorescent stains and interfere with staining and detection of bacteria unless milk-clearing treatments are applied before measurement (Gunasekera et al., 2000). Future epidemiological studies aiming at detecting microorganisms in raw and heat-treated milk need to account for this methodological aspect.

We conclude that the automated most-probablenumber TEMPO method is an inexpensive and rapid alternative to standard culture that is suitable for assessing total bacterial counts in processed and raw milk samples. 
A
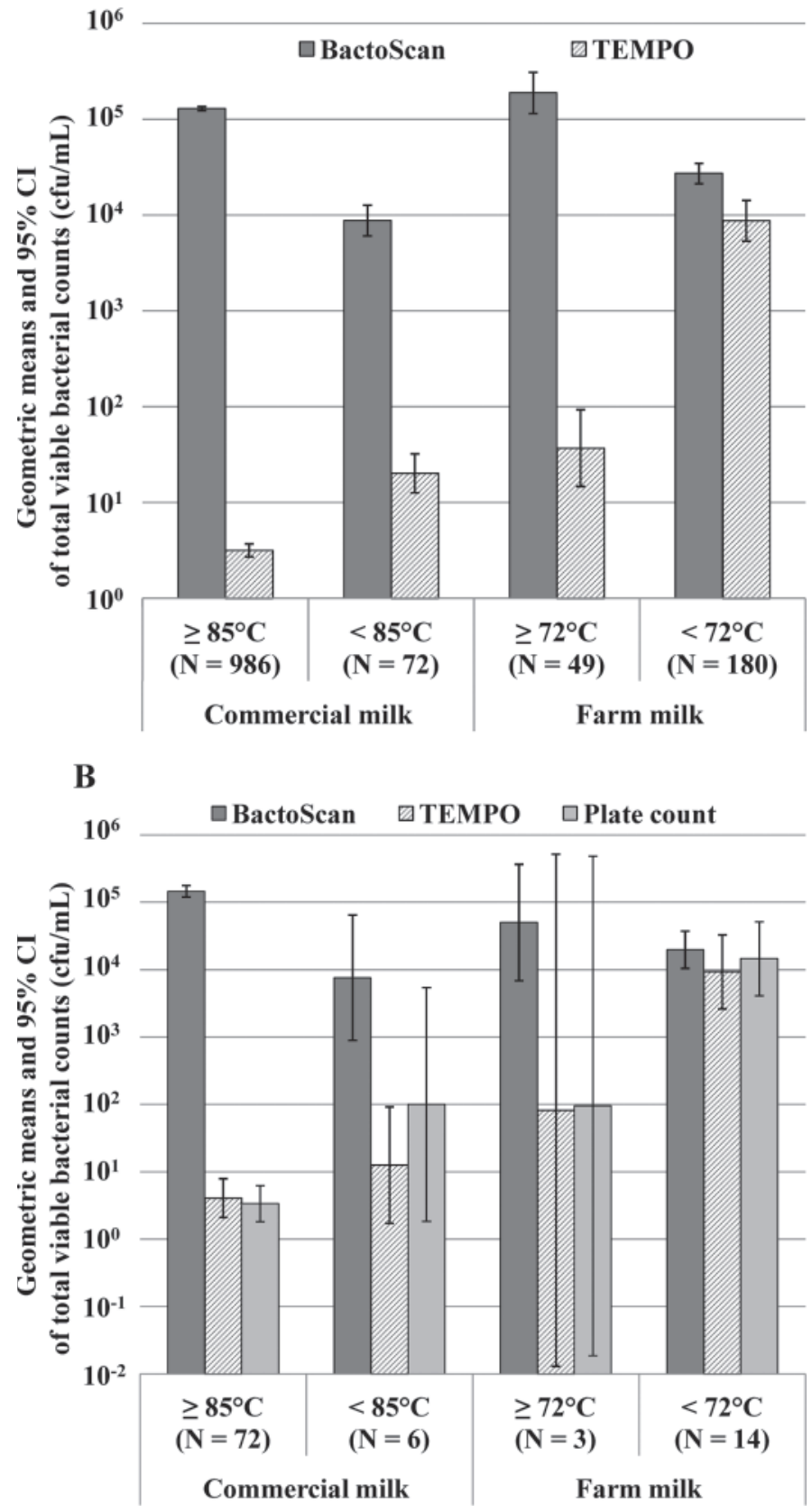

Figure 1. Geometric means and $95 \%$ confidence intervals of total viable bacterial count measured with (A) BactoScan (Foss Analytical, Hillerød, Denmark) and TEMPO method (bioMérieux, Marcy l'Etoile, France) in all 1,287 commercial and farm milk samples and (B) BactoScan, TEMPO, and plate count method in 95 commercial and farm milk samples stratified by milk's heating status.

\section{ACKNOWLEDGMENTS}

This work was supported by a European Union Research grant under the FP6-LifeSCIHEALTH Integrated Program LSH-2004-1.2.5-1 (contract number 018996). We thank Peter C. Lorenzen from the Max Rubner Institut (Kiel, Germany) for the measurement of milk intrinsic enzymes to define milk's heating status. We also thank all members of the GABRIEL study team.

\section{REFERENCES}

Genuneit, J., G. Büchele, M. Waser, K. Kovacs, A. Debinska, A Boznanski, C. Strunz-Lehner, E. Horak, P. Cullinan, D. Heederik, C. Braun-Fahrländer, and E. von Mutius. 2011. The GABRIEL Advanced Surveys: Study design, participation, and evaluation of bias. Paediatr. Perinat. Epidemiol. 25:436-447. http://dx.doi. org/10.1111/j.1365-3016.2011.01223.x.

Gunasekera, T. S., P. V. Attfield, and D. A. Veal. 2000. A flow cytometry method for rapid detection and enumeration of total bacteria in milk. Appl. Environ. Microbiol. 66:1228-1232.

Jasson, V., L. Jacxsens, P. Luning, A. Rajkovic, and M. Uyttendaele. 2010. Alternative microbial methods: An overview and selection criteria. Food Microbiol. 27:710-730.

Loss, G., S. Apprich, M. Waser, W. Kneifel, J. Genuneit, G. Büchele, J. Weber, B. Sozanska, H. Danielewicz, E. Horak, R. J. J. van Neerven, D. Heederik, P. C. Lorenzen, E. von Mutius, and C. Braun-Fahrländer, and the GABRIELA study group. 2011. The protective effect of farm milk consumption on childhood asthma and atopy: The GABRIELA study. J. Allergy Clin. Immunol. http://dx.doi.org/10.1016/j.jaci.2011.07.048.

Perkin, M. R., and D. P. Strachan. 2006. Which aspects of the farming lifestyle explain the inverse association with childhood allergy? J. Allergy Clin. Immunol. 117:1374-1381.

Riedler, J., C. Braun-Fahrlander, W. Eder, M. Schreuer, M. Waser, S. Maisch, D. Carr, R. Schierl, D. Nowak, and E. von Mutius. 2001. Exposure to farming in early life and development of asthma and allergy: A cross-sectional survey. Lancet 358:1129-1133.

International Dairy Federation. 1991. IDF Standard 100B: Liquid milk enumeration of microorganisms colony count technique at $30^{\circ} \mathrm{C}$. International Dairy Federation, Brussels, Belgium.

ISO (International Organization for Standardization). 2000. Milk and milk products - Determination of alkaline phosphatase activity using a fluorimetric method-Part 1: Milk and milk-based drinks. ISO 11816-1:1997; German version EN ISO 11816-1:2000. ISO, Geneva, Switzerland.

Strachan, D. P. 1989. Hay fever, hygiene, and household size. BMJ 299:1259-1260.

Suhren, G., and H. G. Walte. 1998. First experiences with automatic flow cytometric determination of total bacterial count in raw milk. Kieler Milchwirtschaftliche Forschungsberichte 50:249-275.

Torlak, E., I. M. Akan, and M. Gokmen. 2008. Comparison of TEMPO EC and TBX medium for the enumeration of Escherichia coli in cheese. Lett. Appl. Microbiol. 47:566-570.

Waser, M., K. B. Michels, C. Bieli, H. Floistrup, G. Pershagen, E. von Mutius, M. Ege, J. Riedler, D. Schram-Bijkerk, B. Brunekreef, M. van Hage, R. Lauener, and C. Braun-Fahrlander. 2007. Inverse association of farm milk consumption with asthma and allergy in rural and suburban populations across Europe. Clin. Exp. Allergy 37:661-670. 